\title{
The Santos-São Vicente LRV: pioneering medium capacity rail transport in Brazil
}

\author{
C. Macedo ${ }^{1,2}$ \& J. Waisman ${ }^{1,3}$ \\ ${ }^{1}$ Sistran Engenharia, Brazil \\ ${ }^{2}$ Department of Transportation, \\ Mackenzie University School of Engineering, Brazil \\ ${ }^{3}$ Department of Transportation, \\ Polytechnic School of the University of São Paulo, Brazil
}

\begin{abstract}
Two former experiences (Rio de Janeiro and Campinas) with light rail vehicle (LRV) operations in Brazil have failed, mainly due to lack of adequate planning and design. Following the example of Western European cities, many Brazilian cities are currently planning, designing and constructing LRV sytems. This is the case of Rio de Janeiro (Olympic Games 2016), Cuiabá (Soccer World Cup 2014), Maceió and Santos - São Vicente. The latter is an interesting study case, since it relates to two cities within a metropolitan area (the Baixada Santista Metropolitan Area). An extension of this project will connect a third city (Praia Grande). Its first section (Barreiros - Porto) is currently under construction and will be operational by mid-2014.

This project, as all other medium capacity projects in Brazil, is designed to provide urban renewal and sustainability, improve connectivity between cities as well as the quality of public transport services.

Keywords: transportation in metropolitan regions, LRV design, architecture, engineering.
\end{abstract}

\section{Introduction}

Past efforts to operate modern tramways in Rio de Janeiro and in Campinas failed and were discontinued shortly after inauguration. Since then, public transportation in Brazilian cities has consisted almost exclusively of buses. 
More recently, some Brazilian cities have started to design and construct new tramway systems: Cuiabá (state capital - under construction, forecasted for the Soccer World Cup 2014), Rio de Janeiro (state capital - under construction, forecasted for the Olympic Games 2016), Baixada Santista Metropolitan Region, forecasted for mid-2014) and Maceio (state capital, under design, forecasted for 2015/2016).

These new projects bring the latest technological developments applied in many Western European cities to Brazil.

This paper deals with the Baixada Santista Metropolitan Region (BSMR) tramway system, connecting the cities of Santos and São Vicente, intended to be the first tramway to operate in Brazil.

\section{The Baixada Santista Metropolitan Region (BSMR)}

The BSMR, which houses 1.8 million inhabitants, is one of the four metropolitan regions in the State of São Paulo. It encases 9 municipalities, of which Santos and São Vicente are the most important.

Santos (450,000 inhabitants) is Brazil's largest and most important port and will be the headquarters of the pre-salt oil exploitation; São Vicente (360,000 inhabitants), a residential city, shares the São Vicente island with Santos. Continuous urbanization connects both of these cities.

Santos had a traditional tramway system for almost four decades, which, after being discontinued in the mid-sixties, was replaced by diesel buses and trolleybuses.

Nowadays, a metropolitan bus service connects both cities and each one has its own municipal service (Santos operating with diesel buses and São Vicente with vans).

The modal shares of daily trips in the BSRM are as follows:

- $\quad$ Public transportation: 30\%;

- Bicycles and motorcycles: $14 \%$;

- $\quad$ Private cars: $56 \%$.

The 'daily trips per habitant' index is 1.42 for Santos and 1.32 for São Vicente.

\section{The new tramway}

During the late $19^{\text {th }}$ century, coffee exportation stimulated the construction of a railway between the Santos port and the São Paulo state hinterland. Along the years, the cargo transport moved towards manufactured goods and a passenger service was established between three municipalities (Praia Grande - São Vicente - Santos). These services (cargo and passenger) were discontinued 15 years ago.

The former railway crossed the Santos and São Vicente areas, and as the populations of these cities grew and urbanization expanded, the railway line became a severe barrier, restricting the connection between these areas. Even 
when the railway services were discontinued, the railway tracks were not removed, forcing local authorities to improvise temporary crossings.

Due to the economic importance of both cities, the São Paulo State Government carried out several studies involving the use of the old railway right of way.

Comparisons between BRT and tramway (LRV) alternatives led to the rail solution being chosen. This choice would improve the supply and quality of public transportation services between the two cities.

The tramway design established two construction stages:

\section{1 $1^{\text {st }}$ stage}

Barreiros (São Vicente) - Port (Santos) (10.67 km) (Figure 1);

Conselheiro Nebias (Santos) - Valongo (downtown Santos) (4.5 km);

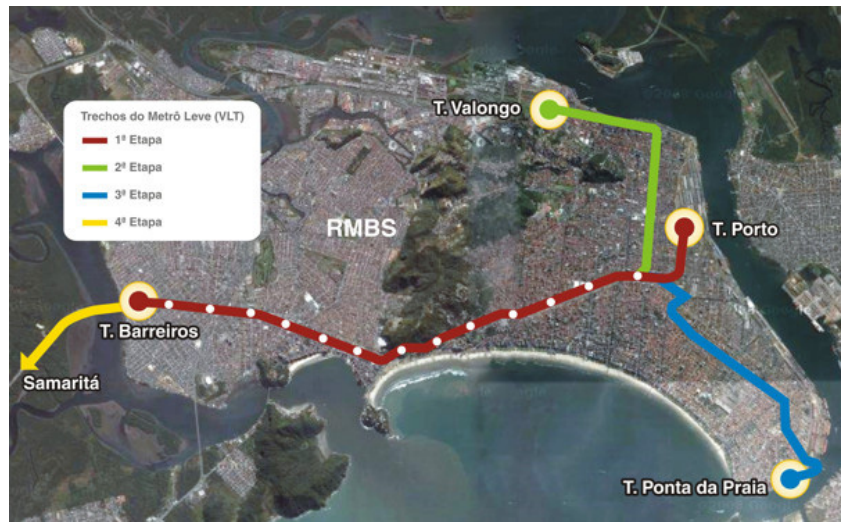

Figure 1: The Baixada Santista Metropolitan Region LRV network.

\section{$3.22^{\text {nd }}$ stage}

Conselheiro Nebias (Santos) - Ponta da Praia (Santos) $(4.0 \mathrm{~km})$;

Barreiros (São Vicente) - Tatico (Praia Grande) $(14.0 \mathrm{~km})$.

The Barreiros - Porto segment is presently under construction and test operations are scheduled to start in June 2014.

The tramway alternative was selected due to many different factors as follows:

- the possibility of implementing an urban renewal process along the railway tracks and improving the connectivity between urban areas of both cities;

- $\quad$ the use of a non - polluting renewable source of energy;

- the reduction of the number of buses in circulation and operation of an integrated system (tramway - bus);

- $\quad$ the provision of high quality transport for increasing demand (estimated at $120,000 \mathrm{pax} /$ day); 
- $\quad$ the deterring of private transportation and reduction of traffic jams;

- $\quad$ the improvement of overall environmental conditions.

Researchers have studied the use of the existing rail right of way for public transport purposes for almost 20 years. Even before the LRT alternative selection, a strong citizen's movement came into action to renew the area's urbanization and to implement new public transportation services.

The next section describes the main features of the chosen solutions as well as the design characteristics.

\section{Project characteristics}

The Barreiros - Porto segment (10.67 km long) has the following characteristics:

\subsection{Operational}

Even though a time-integrated fare exists, there is no other type of integration among the buses. This means that the use of an intercity bus and a local bus requires the user to pay two different (and full) fares.

The tramway will operate as a trunk line (22-vehicle fleet) fed by transversal bus lines.

A re-organization of all bus system services will reduce the existing bus fleet by $23 \%$.

A modern fare collecting system will provide operational and temporal integration for passengers using different transport modes. Pre-boarding fare payment equipment will be placed at all tramway stops and boarding/disembarkment will occur in two multimodal terminals (Barreiros and Porto) (at the ends of the line); two transfer points (larger stops) (São Vicente and Conselheiro Nebias) and 12 stops. The average distance between stops is $700 \mathrm{~m}$. Stops will last 15-40 seconds and headways will be 5 minutes during peak hours.

\subsection{Urban renewal}

The LRT project contains three different segments, each with specific characteristics:

- $\quad$ from Barreiros to Bernardino de Campos, the tramway will run along the existing railway right of way in the avenue median;

- $\quad$ from Bernardino de Campos to Conselheiro Nebias the tramway will run along the Francisco Glicerio Avenue (a major arterial) median;

- $\quad$ from Conselheiro Nebias to Porto the tramway will run along the existing railway right of way between several buildings.

A large amount of inadequate transversal crossings, most of which cause many traffic conflicts, were the most complex issues regarding the project. This meant that the LRT urban insertion required much attention during the urban network design process. 
The tramway will run in an exclusive segregated lane with 13 signalized crossings, all designed to improve connectivity between urban areas and safe traffic operations. The chosen alternative avoids left turns in order to reduce LRT track maintenance.

The tramway project will provide a new landscape with intense vegetation, a new bikeway along the tramway line, new sidewalks, traffic signalization (tramway, general traffic, bicycles and pedestrians) and street lighting.

The project contemplates the removal of old existing barriers and the improvement of connections between streets that cross the tracks.

\subsection{Rolling stock and tracks}

The adoption of a modern, non-pollutant and noiseless vehicle was one of the goals of the project. The LRT will replace (and consequently reduce the fleet of) the diesel bus in a large extension.

Vossloh Spain will provide the rolling stock (22-vehicle fleet). Vehicles will be articulated and $44.00 \mathrm{~m}$ long with a continuous platform (gangway connections) to allow for the movement of passengers within vehicles. All vehicles will be equipped with $\mathrm{AC}$ systems, automatic doors on both sides and passenger information displays (Figure 2).
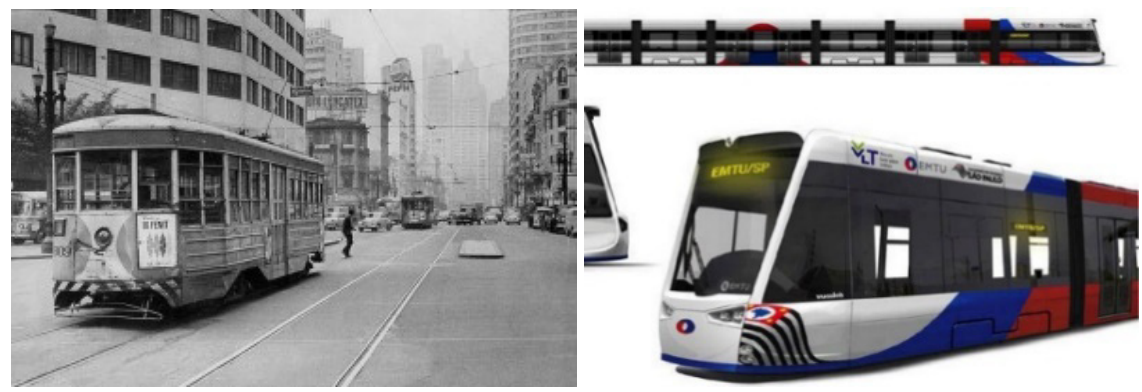

Figure 2: Old tram and new LRV.

Maximum vehicle capacity: 400 pax $\left(6 \mathrm{pax} / \mathrm{m}^{2}\right)$.

The tracks' characteristics will be (Figure 3):

- $\quad$ gauge: $1,435 \mathrm{~mm}$;

- $\quad$ maximum superelevation: $150 \mathrm{~mm}$;

- $\quad$ minimum radius: $100.00 \mathrm{~m}$ (max. speed: $70 \mathrm{~km} / \mathrm{h}$ ) (along the line) and $20.00 \mathrm{~m}$ (max. speed: $20 \mathrm{~km} / \mathrm{h}$ ) (in the maintenance yard);

- $\quad$ maximum grade: $6 \%$;

- $\quad$ rail: R55NK (embedded) on a concrete foundation and concrete filling. Natural grass all along the line. Crossings with concrete pavement. 


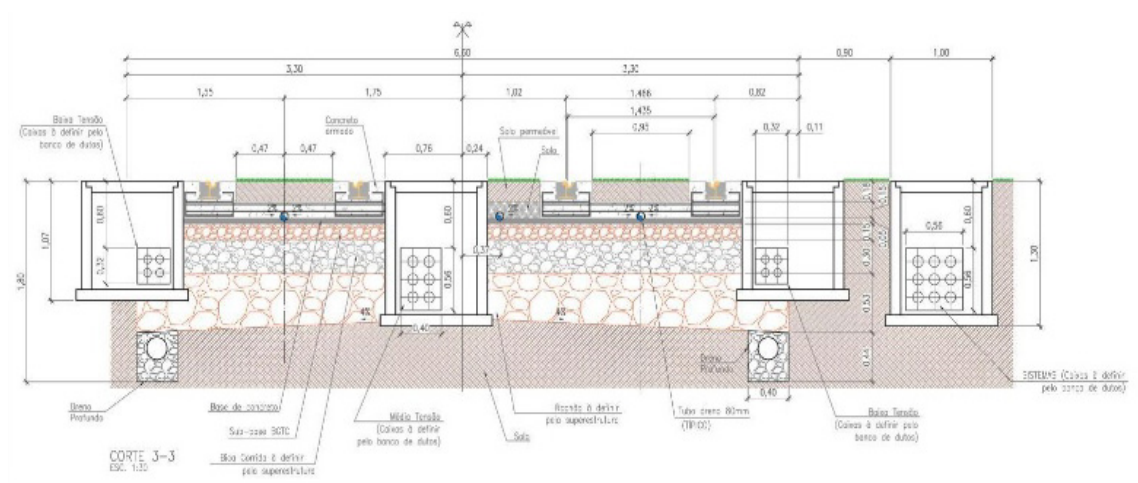

Figure 3: LRV double track.

\subsection{Construction stage}

An important intervention along the rail axis will provide an LRT friendly insertion in the whole area.

Due to the urban renewal process, construction will be extensive and meaningful. The Brazilian consortium of contractors (Queiroz Galvão and Trail) will provide these works, which mainly consist of: (Figure 4, 5 and 6)

- rehabilitation of all street systems along the tracks (drainage and pavement);

- removal of an old viaduct and construction of a new one to allow the passage of the LRV;

- $\quad$ enlargement of an existing railway tunnel to allow the construction of two tracks;

- $\quad$ construction of three new bridges over existing flood regulation channels;

- $\quad$ construction of a bikeway all along the tracks.

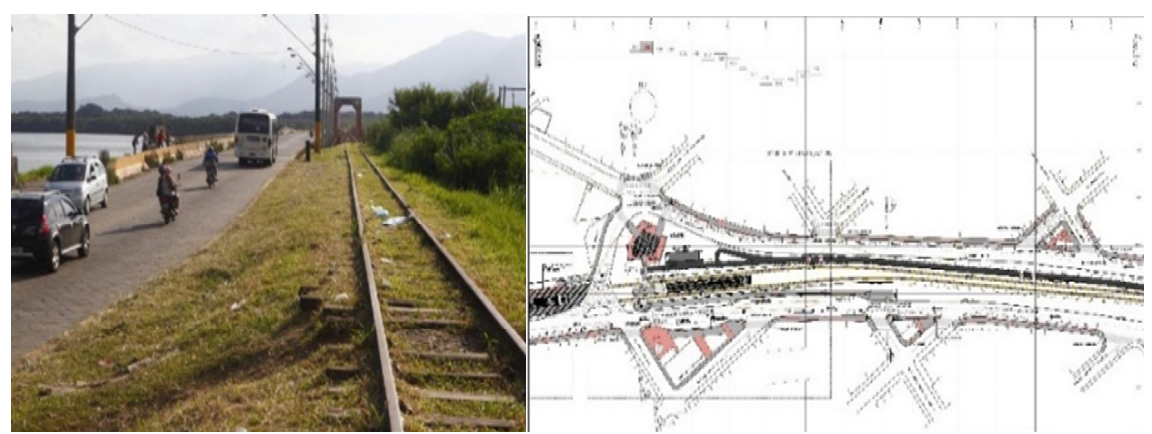

Figure 4: Existing railway track and urban renewal. 

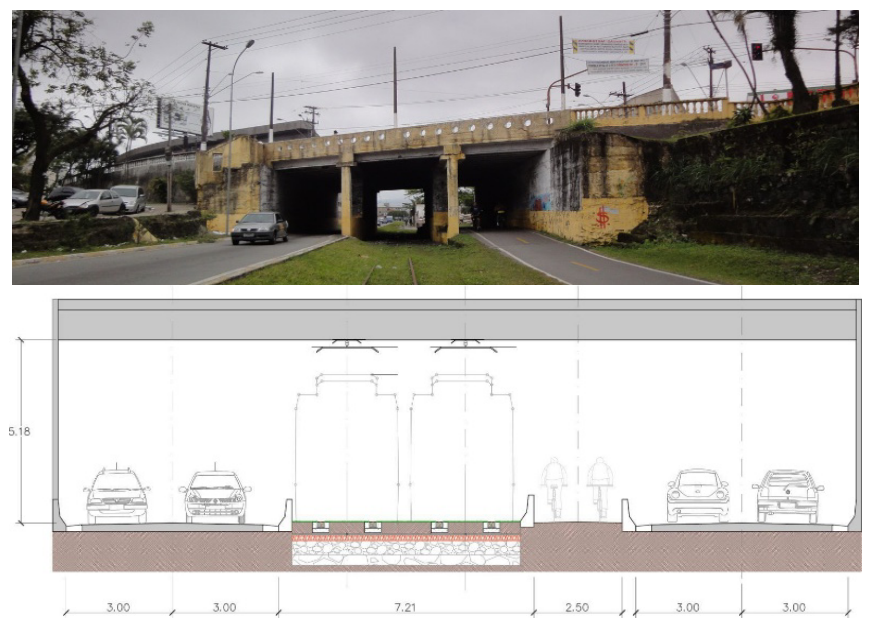

Figure 5: Old viaduct (one track) and new viaduct (two tracks).

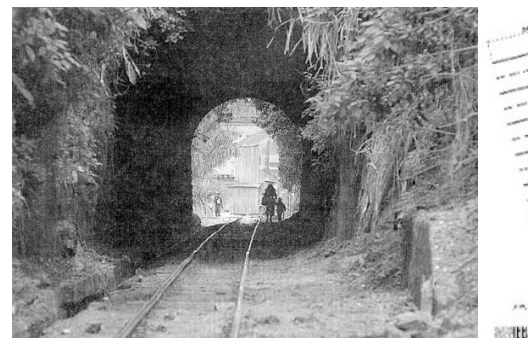

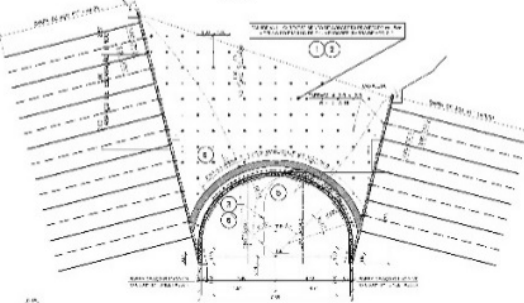

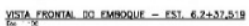

Figure 6: Old railway tunnel and new LRV tunnel.

The foundation, structure and embankment designs all demanded special attention due to bad soil conditions.

\subsection{Stops and terminals}

Since São Vicente is mostly a residential area and Santos concentrates the majority of jobs, an intense passenger flow is expected, requiring special attention to LRT stops and terminals, where large amount of daily embarkments/disembarkments are likely.

All stops and transfer points were designed to be bi-directional and to have a unique central platform (50.00 m long and $5.10 \mathrm{~m}$ wide), automatic doors (between the platform and the vehicle) and public access through one of the ends (Figure 7).

Stops (built area: $310.00 \mathrm{~m}^{2}$ ) were conceived to permit on-level passenger boarding/disembarkment, which eases access to all passengers, especially the handicapped. Comfort and safety features received special attention.

The architecture design is supposed to create a landmark in the cities and is well adapted to the climate conditions. 
Only the São Vicente transfer point will have bus platforms $(200.00 \mathrm{~m})$ for multimodal integration (Total area: $1,550 \mathrm{~m}^{2}$; built area: $310.00 \mathrm{~m}^{2}$ ).

All stations will be equipped with passenger information displays and a CCTV system.

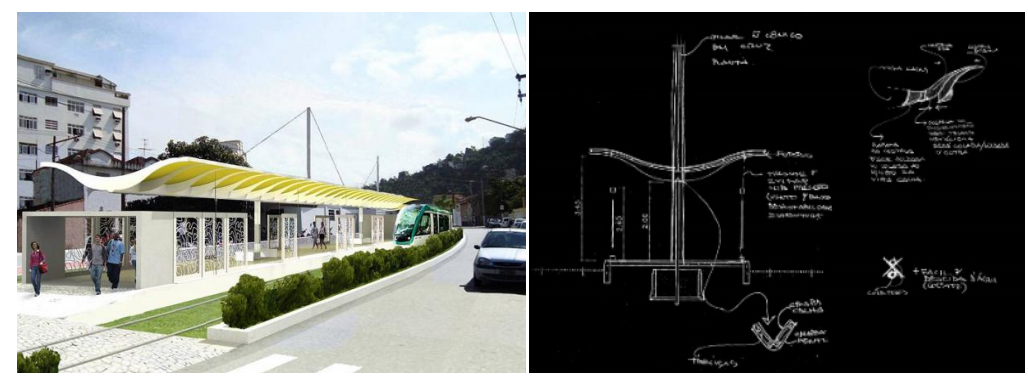

Figure 7: LRV stop.

\subsection{Porto and Barreiros Terminals and maintenance facilities}

Porto and Barreiros Terminals (at opposite ends of the line) will be adjacent to the maintenance yard and will follow the stop's standard.

As in all rail services, this area is intended to be the "core" of the whole transportation system.

Available area restrictions at Porto required that the administrative and maintenance buildings be three stories tall.

The system's main maintenance area will be located at Porto and comprise an administrative building/control center (area: 2,600 $\mathrm{m}^{2}$ ), maintenance facilities (area: 6,800 $\mathrm{m}^{2}$ ), maintenance equipment, parking space for a large LRV fleet (33 vehicles $-8,600 \mathrm{~m}^{2}$ ) and a substation (Figure 8).

The Barreiros area is supposed to assist tramway operations (a parking space is destined for three vehicles) and provide light maintenance when needed. The total constructed area is of $313.00 \mathrm{~m}^{2}$.

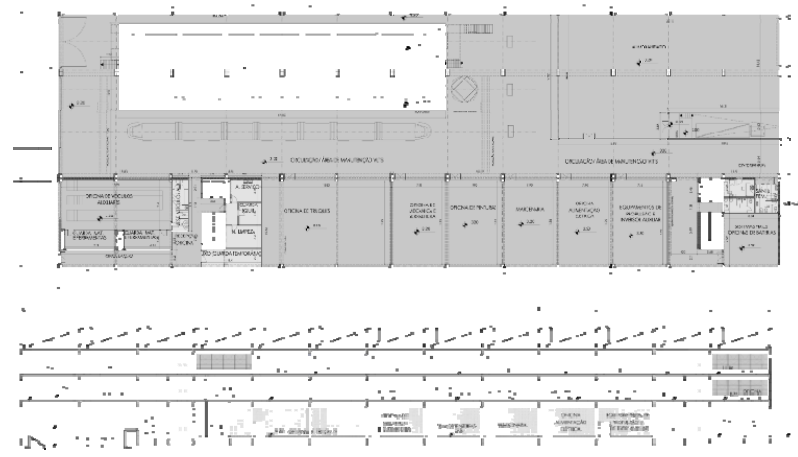

Figure 8: Maintenance building. 


\section{Electrical energy supply and catenary: signalling and control}

The project specifications follow the existing patterns found in many LRT systems in Western European cities.

All the substations will be located along the line and at the terminals. The local concessionary will supply energy at $13.8 \mathrm{Kv}$ (Figure 9).

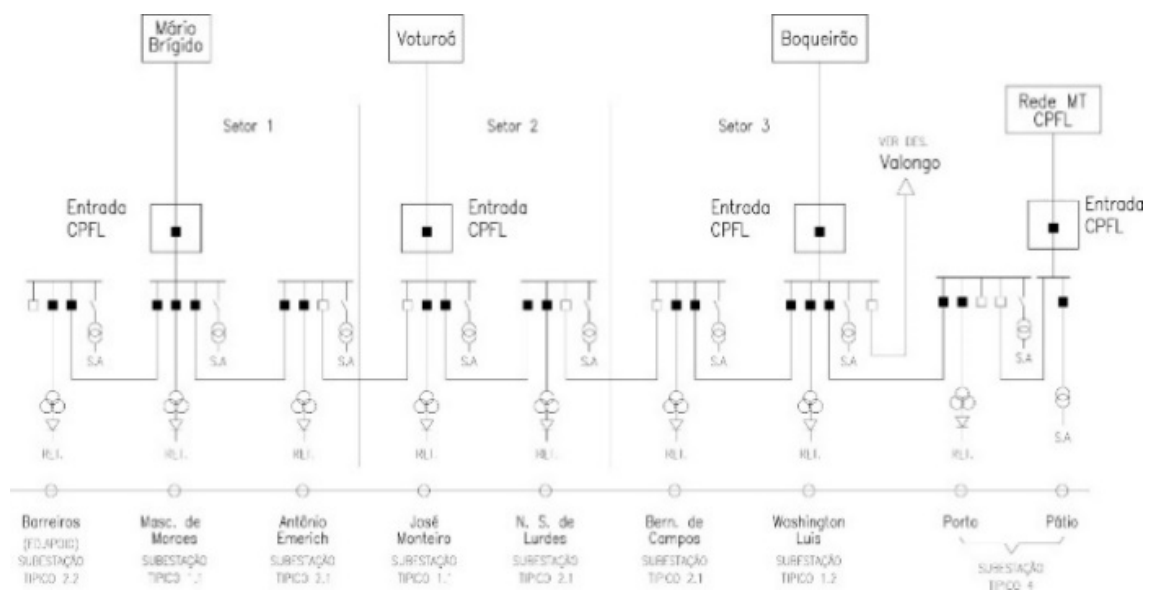

Figure 9: Electrical energy supply.

Tension at the catenary will be $750 \mathrm{Vcc}$ and a flexible assembly system was adapted.

The signaling and control system design comprises the signaling with all LRV crossings/general traffic and pedestrians, signaling along the line, telecommunications, radio-communication, chronometry, passenger information, sonorous system, TCCC, fare collection system and centralized control center.

The LRT driver will operate traffic lights along the tracks. The signaling systems will provide a green wave for LRT operation and guarantee an average speed of $20 \mathrm{~km} / \mathrm{h}$.

A German-Brazilian consortium (ADTrans-Ferreira Guedes) will provide the equipment.

\section{Conclusion}

Recent estimates indicate that the total construction costs of the Barreiros - Porto stage are $€ 310$ million.

A feasibility study showed that direct and indirect benefits resulting from the project implementation will counterbalance this cost will by far. There are such 
benefits as public transport passenger travel time savings, reduction of bus and general traffic fuel consumption, decreases in $\mathrm{CO} 2$ emissions, reduction of traffic accidents, urban renewal and overall environmental improvement.

\section{Reference}

[1] EMTU - Empresa Metropolitana de Transportes Urbanos/ Consórcio Projeto VLT (SISTRAN Engenharia Ltda. - Setepla Tercnometal Engenharia S/A), the BARREIROS - PORTO Detailed Design, São Paulo, 2014. 